\title{
Datação diferenciada das planícies vulcânicas lunares através da densidade espacial de crateras de impacto
}

\author{
Paula Dias e Pedro Pina \\ CERENA-Centro de Recursos Naturais e Ambiente, Instituto Superior Técnico, Universidade de Lisboa, Av. Rovisco Pais, 1049-001 Lisboa \\ paula.dias@tecnico.ulisboa.pt, ppina@tecnico.ulisboa.pt
}

\begin{abstract}
Differentiated dating of lunar volcanic plains through the spatial density of impact craters - The great volcanic plains of the Moon, generically known as seas, were emplaced during long periods of time by distinct eruptive events. The identification of the respective geological units within each large plain has been mainly supported by geological interpretations after remote imagery, normally leading to diversified maps that seldom agree with each other. Impact craters, an excellent indicator of the geological history of planetary surfaces, are used to develop an alternative and quantitative methodology for identifying and dating in a differentiated way the great volcanic plains of the Moon through an objective procedure.
\end{abstract}

\begin{abstract}
As grandes planícies vulcânicas da Lua, genericamente conhecidas como mares, foram formadas por diversos eventos eruptivos ao longo de longos períodos. A identificação das respetivas unidades geológicas em cada grande planície tem sido baseada em distintas interpretações geológicas a partir de imagens remotas que conduzem normalmente a mapas muito pouco concordantes. Sendo as crateras de impacto um testemunho do passado geológico das superfícies planetárias, propõe-se explorar o seu arranjo espacial para desenvolver uma metodologia quantitativa capaz de efetuar a identificação e datação diferenciada das grandes planícies vulcânicas da Lua de uma forma objetiva.
\end{abstract}

\section{Introdução}

Os 'maria', plural de 'mare’ em latim, correspondem na Lua às regiões mais escuras da sua superfície. Durante muito tempo, julgou-se que estas regiões, à semelhança da Terra, seriam mares ou oceanos, enquanto as zonas mais claras corresponderiam aos continentes ou 'terrae', plural de 'terra' em latim. Apesar de posteriormente se ter verificado que tal dicotomia continentes-oceanos não tem sentido na Lua, as designações para os principais tipos de superfícies lunares mantiveram-se inalteradas, mesmo no interior da comunidade científica. As 'terrae' correspondem assim às regiões de relevo mais acidentado e de maior altitude sendo por isso também designadas por terras altas. Já os 'maria' correspondem a grandes depressões topográficas (crateras de impacto) preenchidas por material vulcânico rico em ferro e por isso com menor capacidade refletora da energia solar. Estas regiões vulcânicas são verdadeiras planícies pois espraiam-se por grandes extensões e são topograficamente suaves. Ocupam um pouco menos de um quinto de toda a superfície lunar e estão maioritariamente localizadas na face da Lua que está permanentemente visível a partir da Terra, tendo sido criadas ao longo de prolongados períodos em distintos eventos eruptivos [1], evidenciado pelas diferentes composições mineralógicas [2, 3]. Desta forma, cada 'mare’ é constituído por unidades geológicas distintas, ocupando menores áreas, com características mineralógicas próprias e de diferentes idades.

A identificação das fronteiras destas unidades tem sido essencialmente efetuada através de abordagens qualitativas de interpretação geológica em imagens remotas obtidas pelas várias missões espaciais, mas principalmente Clementine e Chandrayaan-1 por terem sensores capazes de obter dados multiespectrais da superfície da Lua. A contagem por tamanhos das crateras de impacto no interior de cada região delineada permite depois estimar as suas idades absolutas através de metodologias aperfeiçoadas e calibradas nas últimas cinco décadas [4]. Por exemplo, o ‘mare’ Sinus Iridum, que tem atraído regularmente a atenção da comunidade científica por ter características muito próprias resultantes de uma evolução geológica complexa como, por exemplo, elevados teores de óxidos de ferro e de titânio. A topografia muito suave também ajudou na sua escolha para o local de aterragem da sonda chinesa Chang'e-3 em 2013 (que afinal acabou por aterrar várias dezenas de quilómetros mais a Sul do que planeado). Sinus Iridum, designação em latim para Baía do Arco-íris, é, no entanto, uma cratera de impacto com cerca de $250 \mathrm{~km}$ de diâmetro localizada a noroeste do Mare Imbrium $\left(45,0^{\circ} \mathrm{N}, 31,7^{\circ} \mathrm{W}\right)$ que se encontra preenchida com material vulcânico (Figura 1a). A sua diversidade geológica tem motivado o interesse de vários autores que, entre outros aspetos, propuseram as suas várias unidades geológicas [5-9]. No entanto, devido à utilização diferenciada de dados em cada estudo e, sobretudo, devido às diferentes interpretações geológicas, os mapas propostos apresentam claras diferenças entre si, não só no número de unidades detetadas, mas também na localização das respetivas fronteiras (Figura 1b).

De forma a ultrapassar tão evidentes e largas discrepâncias propõe-se uma abordagem alternativa para identificar as fronteiras das unidades vulcânicas, baseada em critérios quantitativos e relacionada com a densidade espacial de crateras de impacto. Saber que as superfícies planetárias que apresentam semelhantes distribuições de tamanho de crateras de impacto são da mesma idade permitiu elaborar a solução que consiste em encontrar a fronteira entre regiões de diferente densidade espacial de crateras. 


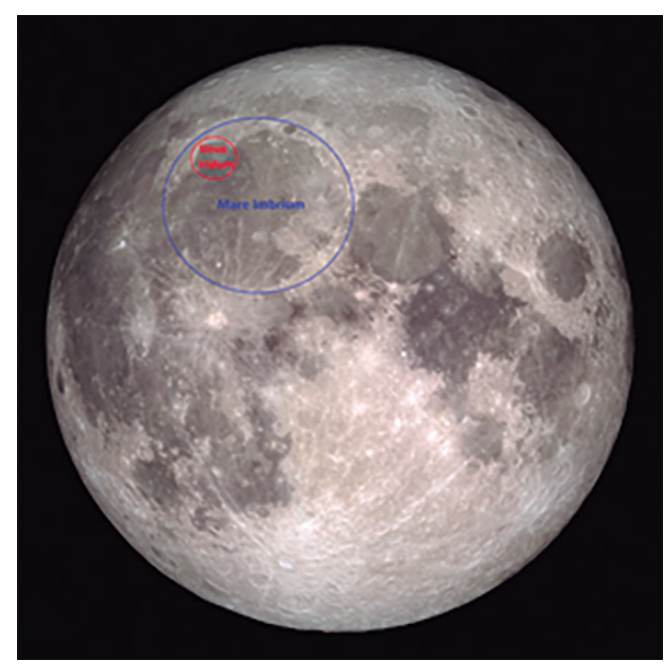

(a)

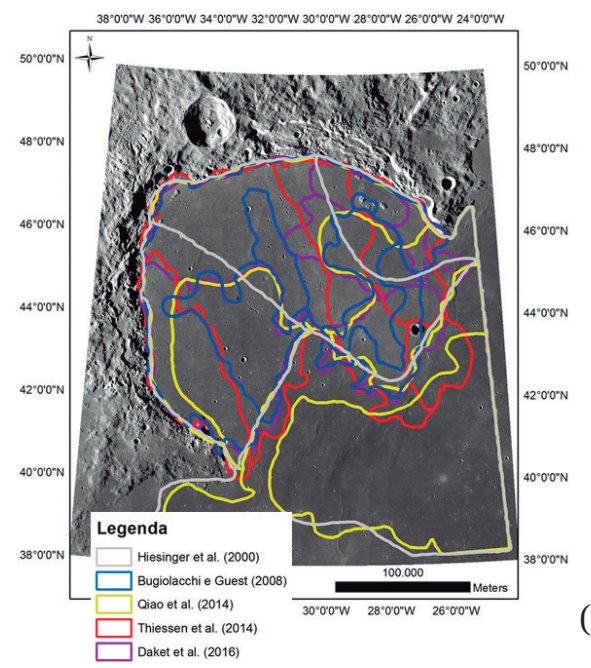

(b)

Figura 1 - Região de Sinus Iridum na Lua: (a) Localização geográfica em Mare Imbrium e (b) Unidades geológicas propostas por diferentes autores [2-6], sobrepostas a um mosaico construído a partir de imagens captadas pela câmara TC a bordo da sonda Kaguya da Agência Espacial Japonesa JAXA [Créditos: USGS, Kaguya].

Este artigo encontra-se organizado da seguinte forma: inicia-se pela descrição do tipo de dados utilizado (secção 2), descrevem-se em seguida os principais passos da metodologia proposta (secção 3) e, por fim, os resultados experimentais que levam à delineação de cinco subunidades litológicas e às respetivas datações, incluindo a sua validação (secção 4).

\section{Dados}

Os dados utilizados no desenvolvimento e validação da metodologia consistem num mosaico de imagens remotas (imagem de fundo na Figura 1b) e num modelo digital de elevação da região de Sinus Iridum (Figura 2).

O mosaico foi construído e disponibilizado pela USGS - United States Geological Survey [11] a partir de um conjunto de imagens captadas pelo sensor TC - Terrain Camera [12] a bordo da sonda japonesa Kaguya, apresentando uma resolução espacial de 7.4 m/píxel.

O modelo de elevação foi construído a partir de medições laser com o instrumento Lunar Orbiter Laser Altimeter (LOLA), a bordo da sonda da NASA Lunar Reconnaissance Orbiter (LRO). O modelo utilizado neste trabalho foi o LDEM 256 que na zona equatorial da Lua tem uma resolução de 256 píxeis por grau, correspondendo na região de Sinus Iridum a uma resolução espacial de 119.5 m/píxel.

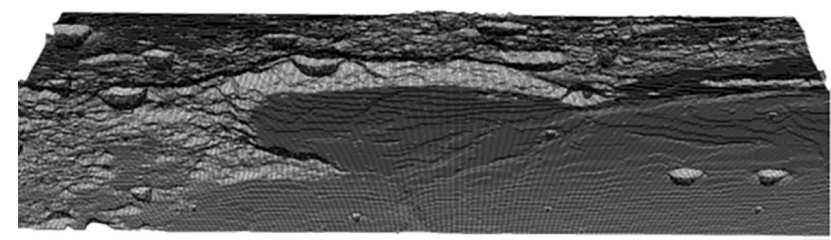

Figura 2 - Representação em perspetiva do modelo digital de elevação da região de Sinus Iridum construído com os dados do sensor LOLA a bordo da sonda Lunar Reconnaissance Orbiter da NASA.

\section{Metodologia}

A abordagem metodológica que se descreve em seguida foi inspirada por alguns trabalhos desenvolvidos por outros autores, relacionados com a criação de mapas de densidade de crateras [12,13] e com a análise da sua aleatoriedade espacial para verificar se tem origem em impactos primários [14]. Desta forma, a metodologia quantitativa de delineação de unidades vulcânicas é constituída por quatro passos principais: i) identificação das crateras de impacto; ii) construção de um mapa de densidade espacial de crateras; iii) delineação objetiva de regiões de igual densidade; iv) datação absoluta de cada unidade através da técnica baseada na distribuição de tamanhos de crateras.

\subsection{Identificação das crateras de impacto}

O mosaico de imagens que cobre a região de Sinus Iridum serviu para identificar todas as crateras com diâmetro (D) superior a $500 \mathrm{~m}$ numa área circular correspondente à região da depressão topográfica original (Figura 3a). Os agrupamentos ou alinhamentos direcionais óbvios de crateras (Figura 3b) não foram considerados visto corresponderem a crateras secundárias, ou seja, crateras formadas por material ejetado na sequência de um impacto primário. O conjunto final é assim constituído por 1316 crateras primárias com um diâmetro médio de $809 \mathrm{~m}$, tendo a de maior dimensão 8666 m. A maioria destas crateras (51\%) apresenta diâmetros no intervalo 500-707 m, sendo a distribuição de tamanhos a que se apresenta no histograma da Figura 4.

\subsection{Construção do mapa de densidade de crateras}

Esta tarefa consiste na criação de um mapa que, a partir de amostras pontuais (centros das crateras), indica a densidade de crateras de impacto em toda a região em análise. No cálculo da densidade é necessário definir dois parâmetros: a dimensão da célula que descreve essa quantidade e uma distância ou raio de procura para efetuar o seu cálculo. A escolha dos parâmetros foi efetuada criteriosamente a partir de diferentes mapas experimentais (Figura 5), sendo o par que melhor descreve o arranjo espacial das crateras da zona de estudo o seguinte: célula de $500 \mathrm{~m}$ e raio de procura igual a $12000 \mathrm{~m}$. 


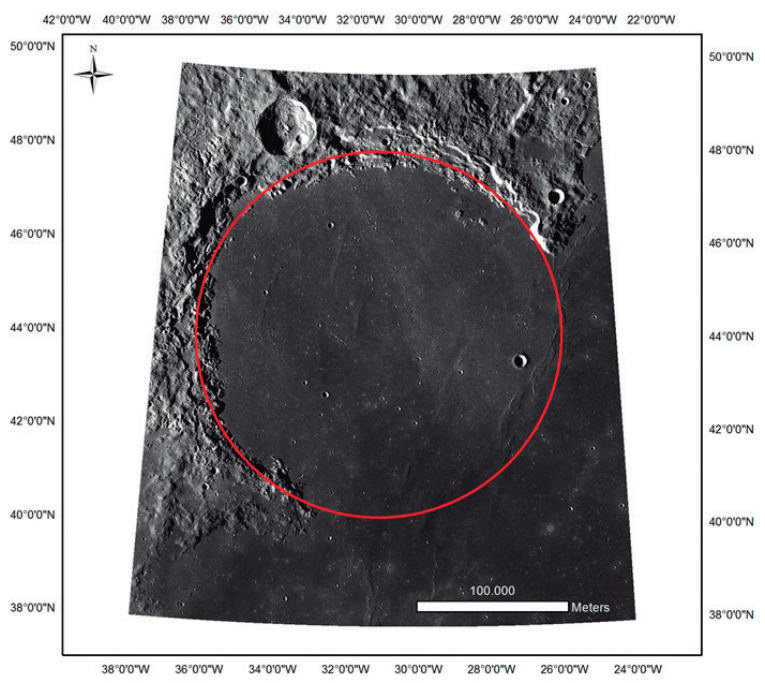

(a)

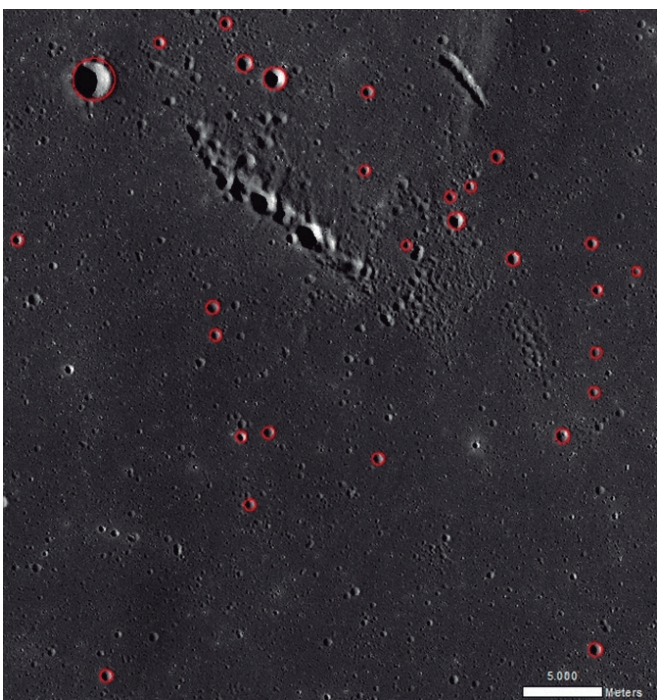

(b)

Figura 3 - (a) Delimitação da zona e estudo em Sinus Iridum e (b) Identificação de crateras primárias de diâmetro D>500 m.

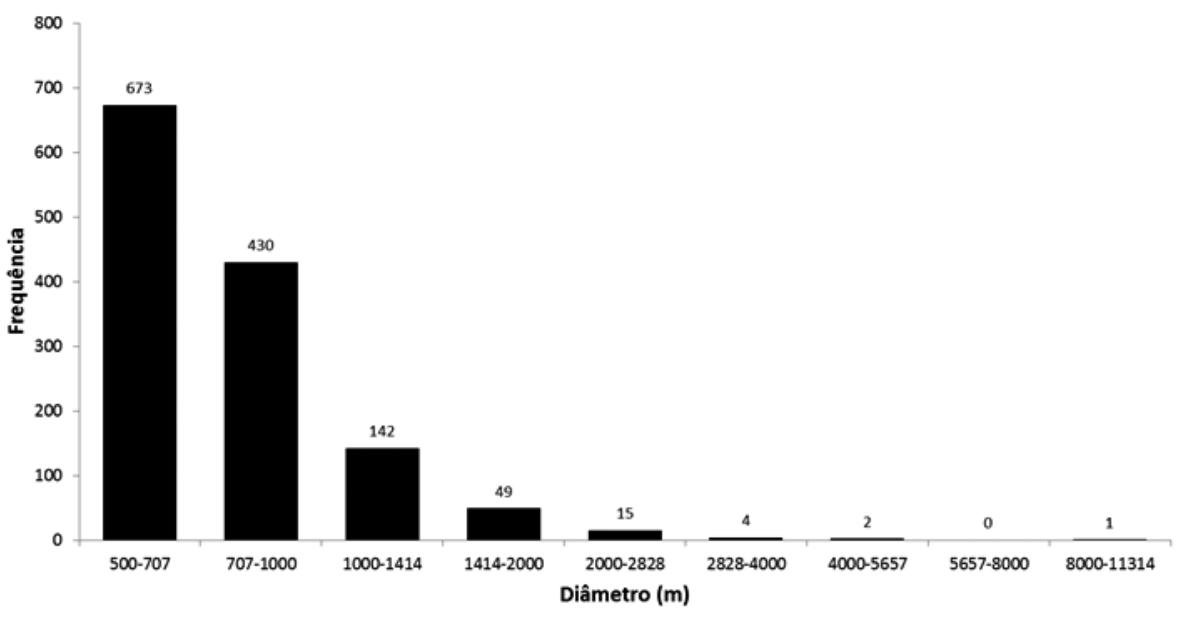

Figura 4 - Distribuição de tamanhos das crateras de impacto de diâmetro D>500 m em Sinus Iridum.

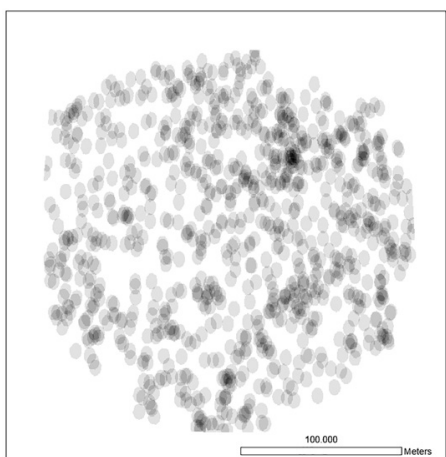

(a)

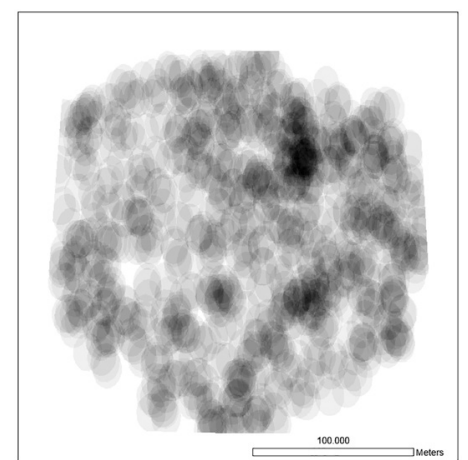

(b)

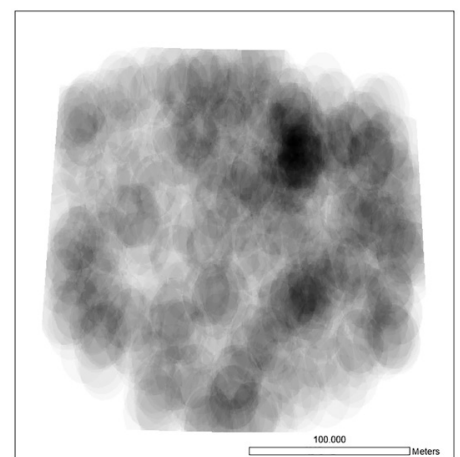

(c)

Figura 5 - Mapas de densidade espacial de crateras com células quadradas de $500 \mathrm{~m}$ e raios de procura de: (a) $500 \mathrm{~m}$; (b) $12000 \mathrm{~m}$ e (c) $20000 \mathrm{~m}$.

\subsection{Delineação de regiões homogéneas}

O conjunto de métodos de análise de imagem dedicado à segmentação dispõe de vários operadores adequados para determinar as zonas homogéneas de uma imagem segundo determinadas propriedades. Um dos métodos mais robustos é a transformação watershed [15], que simula a inundação de uma superfície topográfica a partir de todos os seus mínimos. Nesta analogia, quando a água de duas bacias hidrográficas adjacentes se vai encontrar é construída uma barragem para evitar a sua mistura. A união de todas as barragens corresponde às linhas de festo do relevo, ou seja, às linhas que delimitam as zonas homogéneas da imagem. A transformação watershed não depende de parâmetro algum, podendo a segmentação ser melhorada se se atuar antes e depois da sua aplicação. No caso do pré-processamento é de todo conveniente eliminar mínimos locais, ou seja, mínimos que correspondem a estruturas com menor interesse. Este procedimento é efetuado com filtros morfológicos do tipo abertura-fecho [14], designando-se por Scale (S) o parâmetro associado: quanto maior o seu valor, 
numa escala 0-100, maior será a quantidade de mínimos filtrada. No caso do pós-processamento, a segmentação pode ainda ser simplificada por agrupamento das bacias ou objetos adjacentes que sejam semelhantes, usando o parâmetro Merge (M): quanto maior o seu valor, numa escala 0-100, maior será o número de bacias agrupadas.

O mapa de densidade de crateras de Sinus Iridum foi assim segmentado com a transformação watershed, sendo testados diferentes valores dos parâmetros dos operadores de pré- e pós-processamento (Figura 6). O par que conduziu ao melhor resultado foi $\mathrm{S}=40$ e $\mathrm{M}=95$ em que são delineadas seis regiões com densidades homogéneas de crateras (Figura 6c).

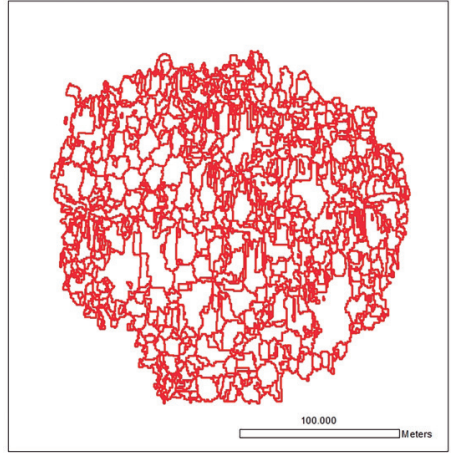

(a)

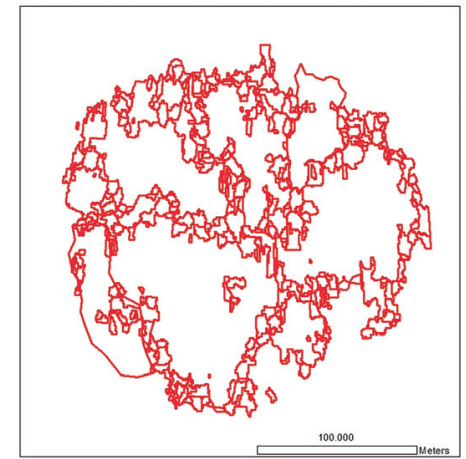

(b)
(Mean 2nd-closest neighbour distance), é comparada com o histograma médio de iguais distâncias simuladas pelo método de Monte Carlo (3000 simulações) de forma a testar a aleatoriedade espacial das crateras em cada unidade (Figura 7). No caso de a avaliação indicar não-aleatoriedade, pode-se editar o mapa e eliminar alguns agrupamentos mais evidentes, voltando-se a testar novamente a aleatoriedade do conjunto modificado. Se o arranjo espacial corrigido for aleatório, a classe de tamanho será incluída no processo seguinte de datação, caso contrário não será considerada.

A elaboração de um modelo de idades para cada unidade geológica permite assim efetuar a sua datação abso-

Figura 6 - Segmentação por watershed do mapa de densidades com diferentes parametrizações: (a) $\mathrm{S}=0$ e $\mathrm{M}=0$; (b) S = 40 e $\mathrm{M}=40$ e (c) $\mathrm{S}=40$ e $\mathrm{M}=95$.

\subsection{Datação absoluta}

O método utilizado para a datação de superfícies recorre à distribuição de tamanhos vs. frequência de crateras [4], supondo que numa dada altura cada unidade litológica da superfície estava num estado em que não possuía nenhuma cratera de impacto, sendo essa época assumida como a correspondente à idade de formação da unidade geológica. A partir desse momento inicial, a superfície irá acumular crateras até ao presente, e cuja quantidade e distribuição de tamanhos é indicadora da idade atual. Por isso, somente as crateras primárias descrevem adequadamente essa acumulação natural.

Apesar de as crateras secundárias óbvias não terem sido consideradas aquando da sua identificação, é provável que existam outras menos óbvias e de menores dimensões que o foram. Este aspeto é mais comum na Lua, já que a permanência das crateras mais pequenas na sua superfície, sem serem apagadas, é bastante mais prolongada do que noutros corpos planetários devido à inexistência de grande parte dos agentes erosivos típicos. Desta forma, antes de se efetuar a datação, recorre-se a um critério adicional objetivo para se detetar eventuais populações de crateras secundárias menos óbvias. Avalia-se assim, em cada unidade, se a distribuição espacial de todas as crateras existentes em cada intervalo de tamanho é aleatória (nesse caso as crateras são primárias) ou se indicam algum tipo de arranjo (nesse caso, existem crateras secundárias). É uma análise quantitativa baseada na média da distância de cada cratera à segunda cratera mais próxima. Tal variável, proposta por G.G. Michael [12] e designada abreviadamente por M2CND luta (Figura 8). Verifica-se que as seis regiões previamente identificadas correspondem somente a quatro idades principais (Figura 9): 3.17 Ga das regiões 3 e 6, 3.36 Ga da região 2, 3.42-3.45 das regiões 1 e 5, e 3.74 Ga da região 4 ( $1 \mathrm{Ga}=1$ milhar de milhões de anos $=10^{9}$ anos $)$.
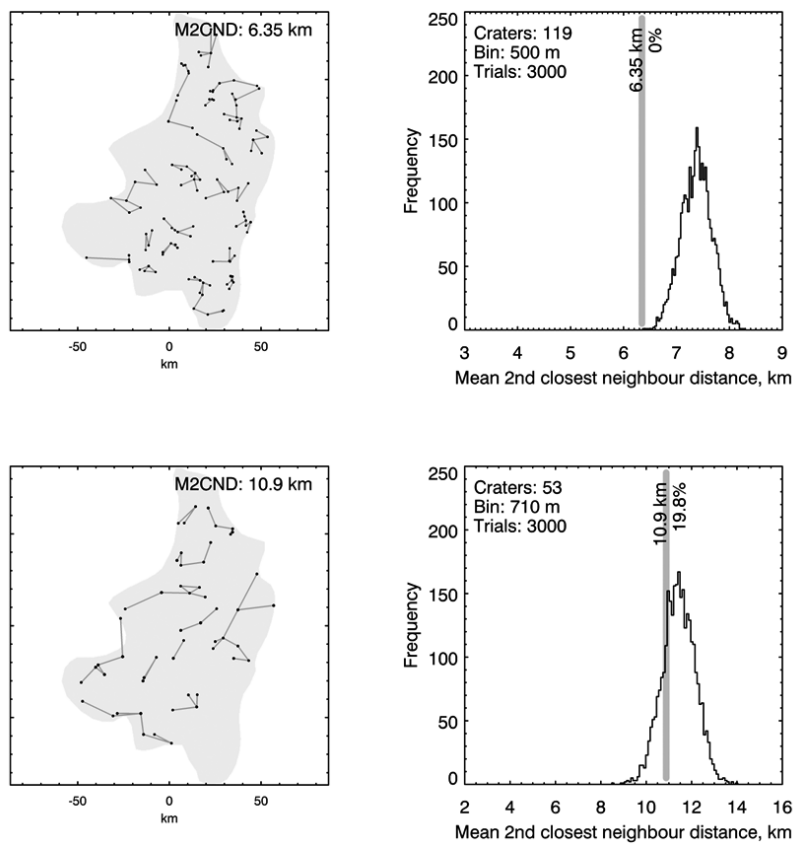

Figura 7 - Aleatoriedade espacial de crateras para duas classes de tamanho numa das subunidades de Sinus Iridum: a de 500 m é não-aleatória (cima) e a de 710 m é aleatória (baixo) (gráficos elaborados com a aplicação freeware Craterstats 2.0 [16]). 


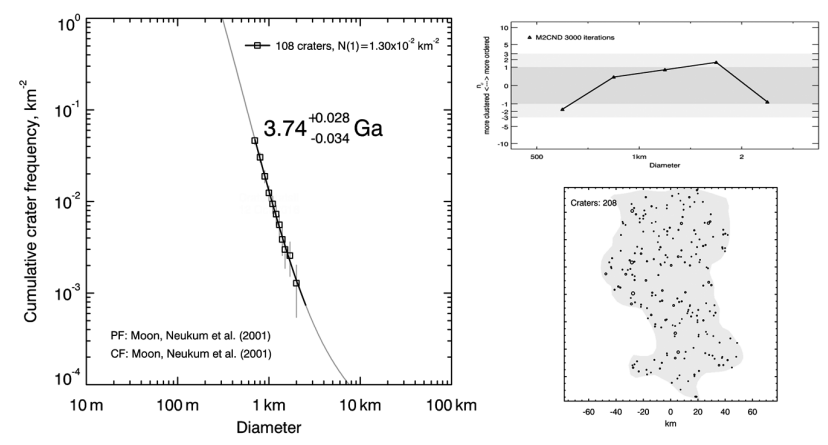

Figura 8 - Datação absoluta de uma unidade vulcânica de Sinus Iridum após ajuste da frequência cumulativa de crateras de dimensões 0.71-2 km à isócrona de 3.74 Ga (gráficos elaborados com aplicação freeware Craterstats 2.0 [16]).

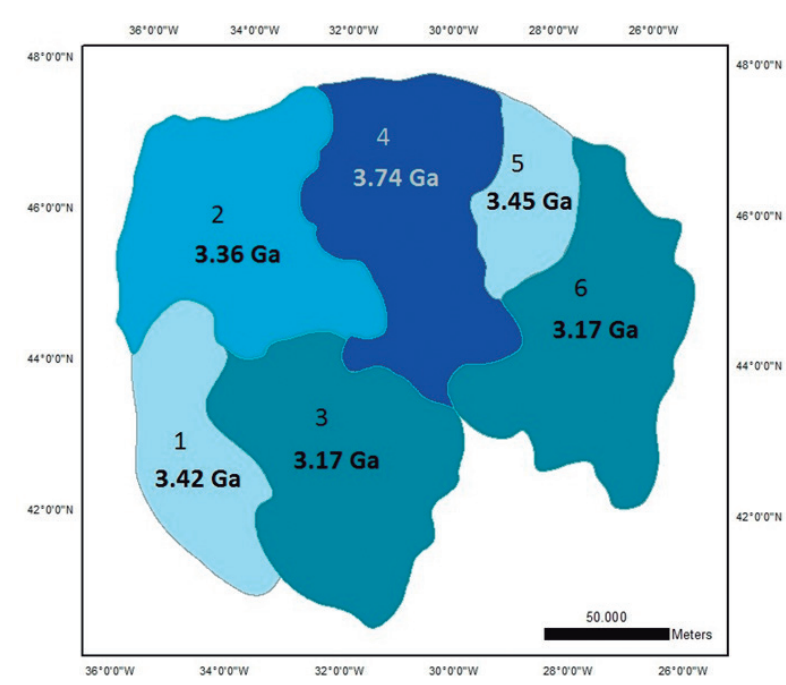

Figura 9 - Modelo de idades absolutas das unidades geológicas em Sinus Iridum identificadas através da nova metodologia.

\subsection{Validação}

De forma a avaliar a bondade das diferenciadas datações e, de certa forma, a própria metodologia, recorre-se a duas abordagens distintas. Na primeira validação, e de uma forma simples e direta, avalia-se se o princípio de sobreposição da estratigrafia se mantém, ou seja, se as unidades mais recentes se sobrepõem às unidades mais antigas. $\mathrm{Na}$ segunda abordagem, mais complexa e requerendo trabalho adicional, verifica-se se as fronteiras entre as diferentes unidades geológicas se mantêm inalteradas com a identificação de crateras mais pequenas.

Para se efetuar a avaliação do princípio de sobreposição basta traçar criteriosamente um conjunto de perfis topográficos recorrendo ao modelo digital de elevação LDEM-256 de Sinus Iridum. Verificou-se em todos eles que as unidades geológicas datadas com uma idade mais recente se sobrepõem às unidades mais antigas, tal como os dois exemplos ilustrativos da Figura 10 demonstram. Verificando-se que o declive de Sinus Iridum se inclina no sentido NO, pode-se concluir que o seu preenchimento com material vulcânico se deu em quatro fases distintas.

No segundo procedimento de verificação foi aplicada a mesma metodologia de quatro passos (identificação de crateras, construção do mapa de densidades, segmentação das zonas homogéneas e sua datação) em quatro regiões quadradas de $30 \mathrm{~km}$ de lado localizadas nas transições entre as fronteiras anteriormente encontradas, usando agora crateras mais pequenas. Foram identificadas todas as crateras de diâmetro superior a $50 \mathrm{~m}$. Devido ao seu elevado número em cada região (entre sete mil e nove mil) foi aplicado um método automático de deteção de crateras baseado no classificador Adaboost $[17,18]$, com posterior validação pericial, acrescentado manualmente as crateras não detetadas e suprimindo as falsas deteções. O mapa de densidades e a sua segmentação por watershed, seguida da datação de cada sub-região identificada foram efetuados em sequência $[19,20]$. Os resultados obtidos são interessantes, mas não são totalmente claros, pois a concordância entre as fronteiras obtidas com crateras mais pequenas ( $D>50 \mathrm{~m}$ ) e maiores ( $\mathrm{D}>500 \mathrm{~m}$ ) é evidente somente para duas das quatro regiões analisadas (Figura 11). A razão para tal, pode dever-se ao facto de o suporte de análise ser demasiado pequeno para uma adequada construção e segmentação do mapa de densidades e também por qualquer destas regiões estar próxima de atingir a saturação de crateras. É, no entanto, um procedimento que apesar de ser inconclusivo, deve continuar a ser investigado, expandindo grandemente as regiões de análise e recorrendo à deteção automática de crateras.

\section{Conclusões}

O craterismo de impacto é o processo geológico mais comum no Sistema Solar e que tem ocorrido ininterruptamente desde a sua formação até aos dias de hoje, apesar do seu reconhecimento ser bastante recente, pois não havia observações diretas da criação das estruturas de impacto. A principal utilidade das crateras de impacto tem sido na datação das superfícies planetárias rochosas, tendo-se explorado neste artigo uma outra vertente, relacionada com a sua densidade espacial para identificar regiões homogéneas nas grandes planícies vulcânicas da Lua.

A metodologia proposta é original e, sendo maioritariamente baseada em procedimentos quantitativos, remove muita da subjetividade inerente aos métodos anteriores de delineação e datação diferenciada das unidades geológicas das planícies vulcânicas lunares.

A validação criteriosa dos resultados obtidos, efetuada de formas distintas, reforça a utilidade da metodologia e a possibilidade de ser utilizada a larga escala em todos as outras planícies vulcânicas da Lua. Necessita, no entanto, de ser acompanhada por métodos automáticos de deteção de crateras, visto uma quantidade significativa destas estruturas não estar ainda catalogada.

\section{Referências}

[1] W.K. Hartmann, R.G. Strom, S.J. Weidenschilling, K.R. Blasius, A. Woronov, M.R. Dence, R.A.F. Grieve, J. Diaz, C.R. Chapman, E.N. Shoemaker, K.L. Jones, Chronology of planetary volcanism by comparative studies of planetary cratering, in "Basaltic Volcanism in Terrestrial Planets", Pergamon, New York, 1049-1127.

[2] P.G. Lucey, D.T. Blewett, B.L. Jolliff, J. Geophys. Res.Planet. 105 (2000) 20297-20305.

[3] J.J. Gillis, B.L. Jolliff, R.C. Elphic, J. Geophys. Res.-Planet. 108 (2003) 5009.

[4] W.K. Hartmann, G. Neukum, Space Sci. Rev. 96 (2001) 165-194. 

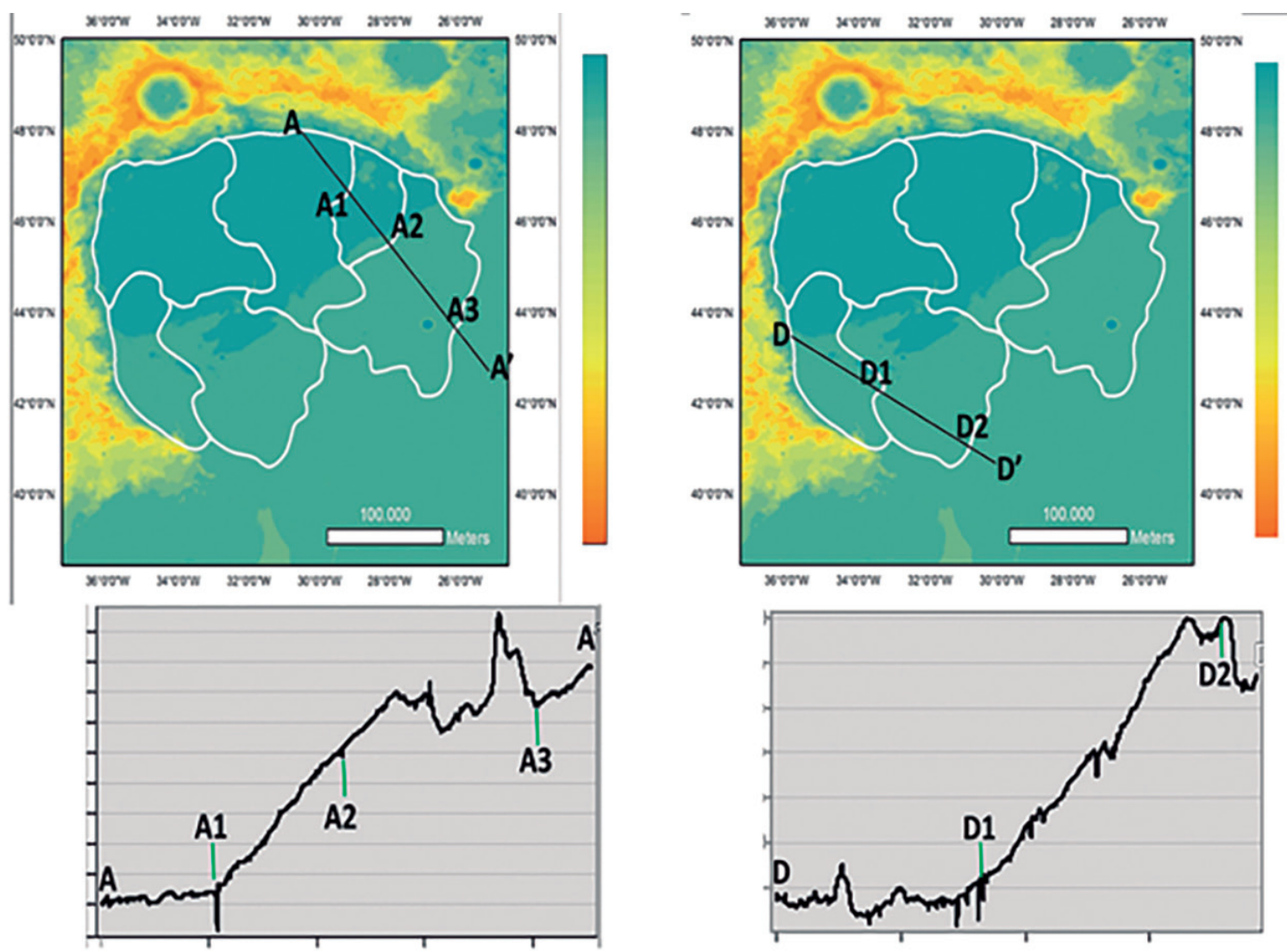

Figura 10 - Perfis topográficos para verificação do princípio de sobreposição da estratigrafia nas idades das unidades geológicas identificadas.

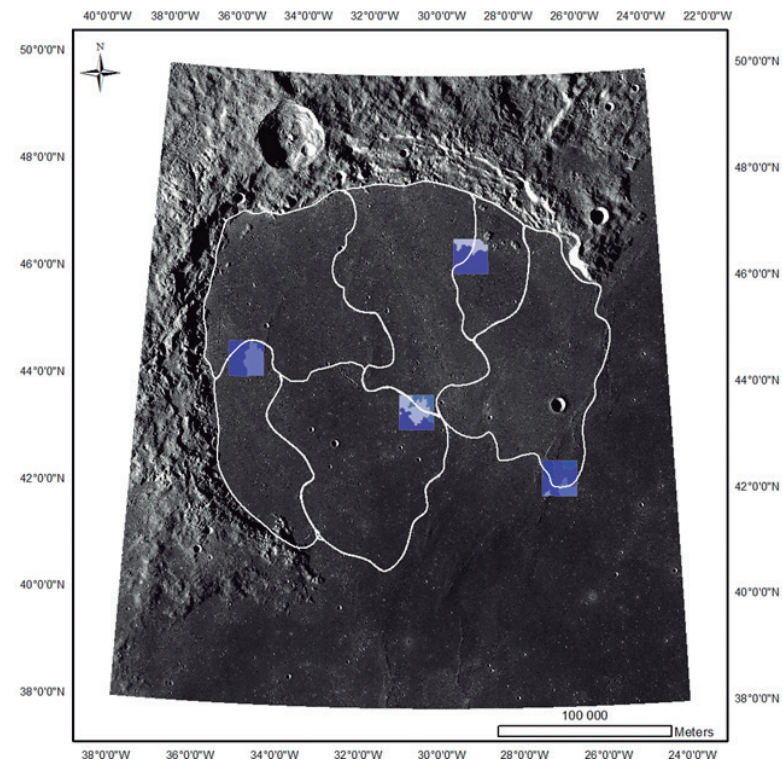

Figura 11 - Aplicação da metodologia com crateras mais pequenas $(\mathrm{D}>50 \mathrm{~m})$ em quatro pequenas regiões-teste localizadas nas fronteiras identificadas com crateras maiores $(\mathrm{D}>500 \mathrm{~m})$.

[5] H. Hiesinger, R. Jaumann, G. Neukum, J.W. Head III, J. Geophys. Res.-Planet. 105 (2000) 29239-29275.

[6] R. Buggiolacchi, J.E. Guest, Icarus 197 (2008) 1-18.
[7] L. Qiao, L. Xiao, J. Zhao, Q. Huang, J. Haruyama, Planet. Space Sci. 101 (2014) 37-52.

[8] F.Thiessen, S. Besse, M.I. Staid, H. Hiesinger, Planet. Space Sci. 104 (2014) 244-252.

[9] Y. Daket, A. Yamaji, K. Sato, J. Haruyama, T. Morota, M. Ohtake, T. Matsunaga, Earth, Planets and Space 68 (2016) 157.

[10] M. Kato, Y. Takizawa, S. Sasaki, SELENE Project Team, LPSC XXXVII (2006) 1233.

[11] C. Isbell, L. Gaddis, P. Garcia, T. Hare, M. Bailen LPSC XLV (2014) 2268.

[12] G.G. Michael, T. Platz, T. Kneissl, N. Schmedemann, Icarus 218 (2012) 169-177.

[13] L.R. Ostrach, M.S. Robinson, LPSC XLV (2013) 1086.

[14] L.R. Ostrach, M.S. Robinson, LPSC XLV (2014) 1266.

[15] P. Soille, "Morphological Image Analysis. Principles and Applications", $2^{\text {nd }}$ edition, Springer, Berlin, 2004.

[16] Craterstats 2.0, Freie Universität Berlin, https://www.geo.fu-berlin.de/en/geol/fachrichtungen/planet/software/craterstats.html

[17] R. Martins, P. Pina, J.S. Marques, M. Silveira, IEEE Geosci. Remote Sens. Lett. 6 (2009) 127-131.

[18] M. Machado, L. Bandeira, P. Pina, LPSC XLVI (2015) 1797.

[19] P. Dias, P. Pina, LPSC XLVIII (2017) 1836.

[20] P. Dias, P. Pina, LPSC XLIX (2018) 1217.

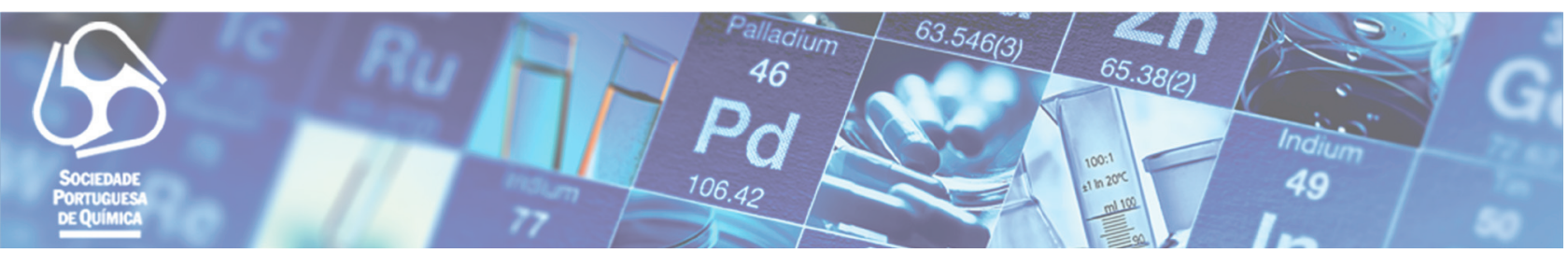

